\title{
CARBON FUNDS: development and transference of technology
}

\author{
Carlos Redondo Gil and A.M. Alonso \\ Department of Electrical and Electronic Engineering. \\ Industrial and Computer School of Engineerings. University of León. 24071-León (Spain). \\ Phone.: +34987291786 carlos.redondo.gil@unileon.es
}

\begin{abstract}
The results obtained, even to the current moment, by the putting in functioning of the mechanisms contemplated in the protocol of Kyoto force the development of mechanisms of support based on the development of flexible projects to promote the transference of technology and in particular the development and the putting in value of the technologies of use of the Renewable Energies. The present document analyzes of synthetic form the definition of the Carbon Funds as financial instruments of support to the Mechanisms of Clean Development (MDL) analyzing on the one hand his definition and structure, distinguished for the Spanish case, and defining for other a model of management.
\end{abstract}

\section{KEY WORDS}

Mechanism for a Clean Development (MDL).Carbon

Funds. Technological Projects Management.

\section{Introduction}

It results from special interest to do the first approach to the challenges and opportunities derived from the Protocol of Kyoto that they imply reducing or controlling the volume of gas emission of greenhouse effect. The Spanish companies must make use of the opportunities opened by the increasing Market of the Carbon, betting on the participation in this type of highly specializing projects and that are provided with the support of the Public administrations.

To the effective reduction of emission they join on the one hand the absorption for sewer pipes of the realized emission, for Spain coded $2 \%$ as maximum and the management of the credits obtained with flexible mechanisms, in case of Spain $7 \%$ of the commitment of reduction, which is equivalent to 100 million tons of CO2e, 60 millions that the Department of Economy and Treasury route will acquire Flexible Mechanisms across funds in Financial Multilateral Institutions IFMs $^{1}$ (in particular the World Bank $\mathrm{BM}^{2}$, The Andean Corporation of Promotion $\mathrm{CAF}^{3}$, The International Bank for the Reconstruction and the Development $\mathrm{BIRD}^{4}$ and the European Investment Bank $\mathrm{BEI}^{5}$ ) and 40 million tons to acquire for the Private sector.

\section{Flexible mechanisms of support to the fulfillment of the guidelines of the Protocol of Kyoto.}

The Protocol of Kyoto foresees the use of three international mechanisms of market - the Commerce of rights of emission (CDE), the Application Joint (AC) and the Mechanism for a Clean Development (MDL) - in order to help the States to fulfill in an economically efficient way the targets of reduction or limitation of emission foreseen in the Protocol. These three mechanisms have been named electric cords in the measurement in which they try to introduce a certain flexibility in the routes to reach the targets of reduction of emission.

In contrast to the commerce of rights of emission, the Application Combines (AC) and the Mechanism for a Clean Development (MDL) are flexible mechanisms based on the project achievement of reduction of emission.

The flexible mechanisms based on projects have, nevertheless, the same economic and environmental logic as the international commerce of rights of emission. On the one hand, these flexible mechanisms allow the States forced by the Protocol of Kyoto to fulfill his targets of reduction or limitation of emission of a more economic form to it to be able to realize a part of the above mentioned reduction of emission in other countries, in that the cost of the same one is lower than the cost that would have to realize it in the territory of the proper State.

\section{Carbon Funds}

The Carbon Funds are financial instruments of collective investment in: The $\left(\mathrm{I}^{\mathrm{st}}\right)$ projects of Joint Application, which reductions or credits of emission derived are quantified by means of Units of Reduction of Emission (URE) that will send the country in which the project is executed; and the $\left(\mathrm{II}^{\mathrm{nd}}\right)$ Mechanism of Clean Development (MDL), whose reductions or derivative credits of emission are quantified by means of Certified Reductions of Emission (RCE), that will send the Executive Meeting of the MDL, the organism of the Convention Marco of the United Nations on the Climatic Change entrusted to supervise the application of the MDL.

The Fund receives economical contributions of his participants well private companies or Governmental Administrations. The Fund invests the resources contributed in projects of AC and of MDL and remunerates the investors, in proportion to his shares, with credits of emission - units of Reduction of Emission or Certified Reduction of Emission) - obtained in the financed projects.

The direct and priority targets of the Carbon Funds are to guarantee reductions of gas emission of greenhouse effect across the buy of exchangeable for cash rights and to promote rules of sustainable development across the mobilization of financial resources. As indirect targets 
can be formulated: (1) generation of income in Countries in development across the sale of Reductions of Emission, (2) to encourage the transference of clean technologies, (3) to promote a socio-economic positive impact of parochial and, character finally, (4) to promote the development of business opportunities.

By means of his participation in the Carbon Funds, the States and companies can obtain credits $A C$ and $M D L$ with less costs of deal and risks than they would have if they had to impel directly the projects.

The first Fund of Carbon created in the world, Prototype Carbon Fund ${ }^{6}$, was thrown by the World Bank in 1999. In him six States take part - Holland, Canada, Sweden, Finland, Norway and Japan - and 17 companies between them, BP, Gaz de France, Electrabel, Deutsche Bank and Mitsubishi - that in whole have contributed 180 million dollars to invest throughout 2004 in at least 30 projects.

Between the chosen projects minihydraulic plants are in Uganda and Costa Rica, plant of use of the biogas of a dump in Latvia, wind parks in Costa Rica and Colombia, plant of biomass from rind of rice in Nicaragua and it plants geothermal and other one of district heating in Poland.

The World Bank and the International Association of Commerce of Emission ${ }^{7}$ threw in July, 2003 the second Fund of Carbon, Community Development Coal Fund, in order to invest exclusively in projects MDL of small scale. Provided initially with 35 million dollars, in the Fund there take part initially the States of Holland, Canada and Italy, together with companies as Basf, Nippon Oil and Endesa.

In parallel, diverse financial institutions and private consultants have started throwing other Carbon Funds. In Spain, for example, the counsel CO2 Spain, with the collaboration of the broker CO2e.com and Baker and McKenzie develops the throwing of the Spanish Fund of Carbon.

The Spanish state presents in October, 2005 the program of work that coordinates the performances of the Departments of Economy and Treasury and the Department of Environment in a meeting with the National Agencies of Development and foresees to close the portfolio of the Spanish Fund of Carbon in the BM in the first months of 2007.

\section{Contributions of Spanish capital in Carbon Funds.}

The Spanish government agrees contributions corresponding to three Carbon Funds managed by the World Bank ${ }^{8}$ : Biocarbon Fund, Carbon Fund for the community development (CDCF) and Spanish Fund of Carbon (FEC).

The Biocarbon Fund the BM was announced in November, 2002. This fund provides financing for projects that kidnap or preserve gases of greenhouse effect in forest and agricultural ecosystems, with the target to obtain credits to the minor cost and at the same time to promote environmental benefits - as conservation of the biodiversity - and improving the conditions of life of the local communities.

Other of the funds of the BM is the Carbon Fund for the Community Development (CDCF), which the World Bank, in collaboration with the Secretariat of the Convention of United Nations on Climatic Change and the International Association for the Commerce of Emission, threw in the World Summit of Sustainable Development (Johannesburgo, September, 2002). This fund finances projects of small scale that reduce gas emission of greenhouse effect in the rural areas of the countries of minor income and it is operative from June, 2003.

In addition to the participation in the previous funds, the Department of Economy and Treasury and the Spain Environment Department signed, to ends 2004, an engagement letter with the World Bank to create the Spanish Carbon Fund (FEC), with which one tries to buy 34 Million tons of CO2e, proceeding from projects that it benefit the global environment simultaneously that transfer clean technologies for the sustainable development of developing countries and countries with economies in transition. The Spanish Fund of Carbon (FEC) supports projects that generate reductions of eligible emission under protection of the regulatory regulation of the flexible mechanisms of the Protocol of Kyoto. This fund is opened for the participation of the Spanish private sector.

In October, 2005 there is created the Latin-American Initiative of the Carbon provided with 47 million Euros destined for the securing of 9 million tons with projects to develop in Latin America; the target in the current moment is to close the portfolio of investments at the end of 2007.

In particular, in case of the Biocarbon Fund, he supposed the contribution in 2005 with 13,3 million dollars, in order to 2 obtained in return millions of tons of CO2. In that of the CDCF, there was acquired the commitment to contribute with 20 million dollars in 2005 in exchange for 4 million tons CO2e. And in case of the FEC, Spain contributed with 27,5 million euros in 2005 being foreseen that in 2015 the entire number contributed to this fund will amount to 170 million euros in order to 34 obtains in return millions of tons of CO2e.

To these initiatives linked to the BM they add the CAF, Latin-American Initiative of the Carbon (IIC), 47 million $€$ to obtain 9 million tons of CO2e; as well as negotiations with the BEI (8 million tons of CO2e) and BIRD (3 million tons of CO2e).

\section{Projects Management linked to Carbon Funds.}

\subsection{Functioning of the Carbon Funds}

Operative structure of the Carbon Funds

\section{Project identification}


1. Energy industry (renewable and not renewable).

2. Energy distribution.

3. Energy demand.

4. Manufacturing industries.

5. Chemical industry.

6. Construction.

7. Transport.

8. Mining and mineral production.

9. Metal production.

10. Fugitive emission in the consumption and production of CFC, PFC y SF6.

11. Use of dissolvers.

13. Management and deposition of residues.

14. Afforestation and Reafforestation.

15. Agriculture.

\section{Making of the plan of investments in that will have especially consideration:}

\section{II.I. The identification of technologies}

Renewable energies (hydraulic and wind), with inclusion of small and medium Projects.

Energy efficiency (you improve industrial processes) reduction of the gas emission of greenhouse effect improving the industrial processes or reducing the gases of discharge (50\%).

Biomass and agricultural garbage.

Solid residues (25\%), there improves treatment and generation of heat and/or electricity from the gases received in the process.

And different, such as: gas projects HFC-23 and N2O, which also are considered.

Technologies promoted by Spanish Carbon Funds applied to the Latin-American Initiative of Carbon:

\begin{tabular}{lc}
\multicolumn{1}{c}{ Technology } & $\mathbf{N}^{\mathbf{o}}$. of Projects \\
\hline Treatment of residues & 32 \\
Hidrofluorcarbonos HFC 23 & 32 \\
Hydroelectric & 18 \\
Wind & 7 \\
Transports & 4 \\
Cogeneration & 4 \\
Energy efficiency & 2 \\
Forest & 1
\end{tabular}

Source: Direction General of International Financing. Department of Economy and Treasury, June, 2006.

II.II. Location of industrial plants, geographical priorities in case of Spain: fundamentally Latin America, East Europe and North of Africa.

Traditionally the factors that worry more the companies at the time of deciding the emplacement of a new industrial plant are included in four categories: level of wages, trade union activity, ambience of manufacture and characteristics of the population ${ }^{9}$, being able to translate each of these categories in such costs as: labor, construction or rent of buildings, taxes, valuations, expenses for energy, water and other provisions, insurances, ...
Along with these costs exist others which estimation is usually difficult, although they contribute of significant form in the election of the emplacement. Between they are the climate of the prevailing business in the area, the possibilities of formation, the attitude of the labor and of the syndicates, the distances to urban centers.

In the sector that occupies us it is of emphasizing the energy problems of Latin America characterized for: (1) the level of access to the electricity, 84 per cent of average, although it comes down to 40 per cent in the rural environment; (2) the low energy efficiency, $5 \%$ of the global emission of gases of greenhouse effect comes from Central Latin America; 3) under index of use of renewable energies; (4) high fragmentation of the energy markets and (5) the need for investments in the sector for volume of investment, risk and insufficiency of local capital.

Areas of investment of the Spanish Carbon Funds ${ }^{10}$ :

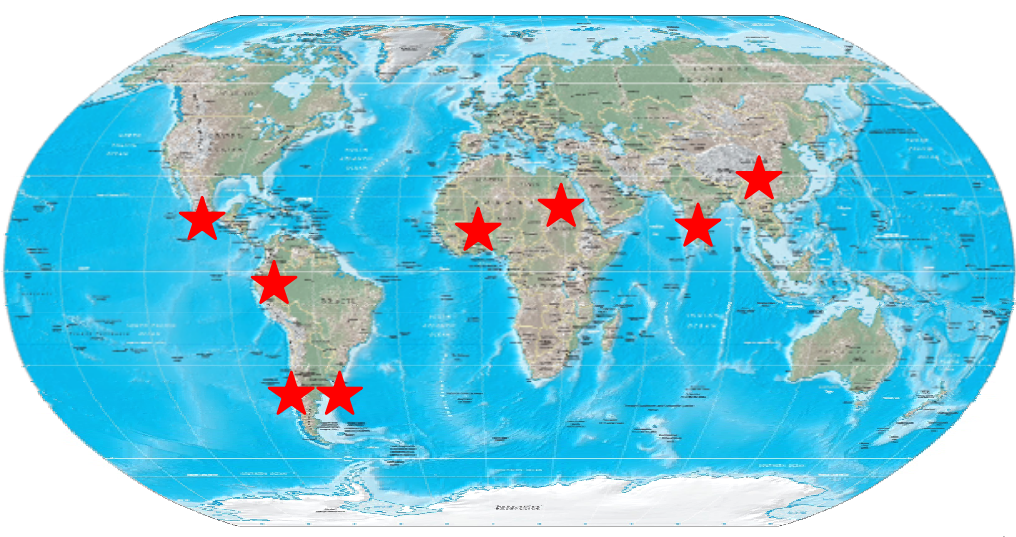

Source: Physical Maps of the World, April 2005 and proper making.

\begin{tabular}{|c|c|c|}
\hline \multicolumn{2}{|c|}{ Country } & Tons of $\mathrm{CO}_{2} \%$ \\
\hline$\star$ & China $^{11}$ & 29 \\
\hline & Ecuador & 18 \\
\hline & Mexico & 13 \\
\hline & India $^{12}$ & 12 \\
\hline & Chile $^{13}$ & 9 \\
\hline & Colombia $^{14}$ & 6 \\
\hline & Uruguay & 4 \\
\hline & Egypt $^{15}$ & 4 \\
\hline$\star$ & Panama & 3 \\
\hline & Mali & 2 \\
\hline
\end{tabular}

Source: Direction General of International Financing. Department of Economy and Treasury, June, 2006. 


\section{II.III. Selection of prime matters.}

The selection of prime matters depends on the technology that allows to develop the process of production, v.g. generation of heat and electricity using agricultural garbage as the husk of rice, the bagasse of the sugar-cane and the residues of the factories of role.

\section{II.IV. Consideration of the environmental not wished} effects ${ }^{16}$ :

- Activities with reversible effects, that is to say that allow to recover the habitat after the putting in practice of certain measurements of recovery of the natural way. Between they can quote the water sanitation, the restoration of the eroded soil, so on. On having planned these activities, it must be foreseen that the entity will turn out to be affected by complementary activities of decontamination and renewal of the vital environment.

- Activities with irreversible effects.

- Activities with accumulative effects, that is to say, that arise as consequence of the sum of activities, being of small interest the individual effect of only one performance.

- Activities with time-delay effects, or what is the same, with effects that are evident in different periods (sometimes several years later) to that there is realized the activity that generates them.

III. Design of the document,

IV. Estimation of reductions of emission (REs),

V. Making of the Plan of pursuit.

VI. Ratification for the Operational designated Entity

VII. Signature ERPA with promoter of the project.

VIII. Initiate process of execution of the project.

IX. Design of the Plan of pursuit and of the model of periodic cross-checks.

\section{$X$. Securing of Certified Reductions of Emission RCEs}

\subsection{Complementary instruments}

The management of Carbon Funds needs the exploitation of hardware of support that must cover the following aspects:

1. Implementation of mechanisms and lines of technical Assistance, to quote: the Coal Finance Assist ${ }^{17}$ of the World Bank, provided with a budget for 5 million euros finances activities of project identification MDL, supports in the process of preparation of documents and training of countries beneficiaries (It initiated 23 projects in 2005); Bilateral FEV and Funds of consultancy in IFMs $^{18}$ : BM, CFI, BID, CAF, BASD, BAFD, BERD.

2. Sources of additional financing: Funds of Help to the development, conversion of Debt and/or lines of financing: COFIDES ${ }^{19}$, Institute of Official Credit and the Private Banking.

3. Establishment of agreements of debt conversion through the inclusion of resultant projects of debt conversion in portfolio of Carbon Funds financing projects that will allow to obtain reductions of additional emission.

4. Favoring the negotiation and interrelation between different institutions that promote the participation of the administrations and of the private sector, v.g. coordination between the BEI and the BERD provided with a target for 100 million euros.

5. Design of products of insurance, v.g. CESCE ${ }^{20}$.

6. And joint of mechanisms of diffusion of the knowledge, v.g. www.carbonfinance.com.

\section{Conclusions}

The member states of the European Union, and in particular Spain, in the search of the fulfillment of the commitments acquired after the ratification of the Protocol of Kyoto have to use, based on his commitments and as support to the domestic measurements, the instruments of flexibility that offers the Protocol of Kyoto to facilitate the fulfillment of the same ones.

At present the World Bank has started and manages different characterized funds because they are constituted by the participation and contributions of governments and companies deprived of developed countries, which investments contribute to the project financing that the gas emission of greenhouse effect reduces or increase the absorptions of the above mentioned gases. With these funds, in addition to contributing to facilitate capital flows towards developing countries or with economies in transition, it manages to put at the disposal of the developed countries an efficient mechanism in cost terms with which to do more flexible the fulfillment of the commitments established by the Protocol.

In Spain in particular there is designed the National Plan of Allocation of rights of emission that it establishes that the entire volume of credits that will be acquired through flexible mechanisms for the first period of commitment of the Protocol of Kyoto will amount to 100 million tons of $\mathrm{CO} 2$ equivalently.

Based on it and across the Departments of Economy and Treasury and Environment, they propos to acquire credits informed by public administrations and private capital, through the constitution of Carbon Funds in multilateral institutions that cover a part of the above mentioned commitment.

The new stage of investment and of transference of technology needs to define efficient procedures of evaluation of risks, selection of stages of investment and instruments of management, simultaneously that makes necessary to identify the possible mistakes of market that stem from the instruments and designed protocols.

The World Bank thinks that there is needed an investment for 300 billion dollars / year until 2030 to assure the energy needs for the developing countries (73 $\%$ electricity, $12 \%$ natural gas, $12 \%$ oil and $3 \%$ coal). China, India, Brazil and Russia will absorb $50 \%$ of the 
investments. In addition to the private and public Investment, one of the principal sources of financing of these needs will be the Carbon Funds in particular from the definition of the stage post-2012.

The income for sales of carbon ranges between 10-50\% of the whole of income in accordance with the type of project.

The Spanish companies must make use of the opportunities opened by the increasing Market of the Carbon, betting on the participation in this type of highly specializing projects with the support of the Administrations.

\section{Acknowledgement}

This work was supported by the Chair of the Renewable Energies of the University of León. Department of Economy and Employment of the Meeting of Castilla y León. General Direction of Energy and Mines.

\section{References}

[1] The Multilateral Funds of Consultancy in 2005 Line multilateral FEV. General Subirección of Financial Multilateral Institutions. ECONOMIC JOURNAL OFICE No 2884 of July 17 on July 30, 2006.

[2] http://www.worldbank.org/

[3] http://www.caf.com/ y Programa Latinoamericano del Carbono (PLAC)

[4] http://www.unesco.org.uy/st-policy/stcoop/indicealfabetico-lista.html

[5] http://europa.eu/scadplus/leg/es/lvb/g24221.htm

[6] http://carbonfinance.org/

[7] http://www.latincarbon.com/organisadores.htm

[8] http://www.minhac.es/Portal/Areas+Tematicas/ Internacional/ Financiacion+internacional/Fondos+de+Carbono/Ficha+ Fondo+BioCarbono.htm

[9] Fernández Sánchez; Dirección de la Producción, l. Fundamentos Estratégicos, Ed. Cívitas. Madrid, 1993.

[10] http://www.icex.es/protocolokioto/default.htm

[11] Instituto Español de Comercio Exterior. Nota sectorial: Energías renovables en China.Oficina Económica y Comercial de la Embajada de España en Pekín. China, 2006.

[12] Instituto Español de Comercio Exterior. Nota sectorial: Energías renovables en India. Oficina Económica y Comercial de la Embajada de España en Nueva Delhi. India, 2005.

[13] Cartera de proyectos pro-Chile. Mayo, 2005.

[14] Cartera de proyectos Grupo de Mitigación de Cambio Climático. Ministerio de Ambiente, Vivienda y Desarrollo Territorial. Colombia. Mayo, 2005.

[15] http://www.gefweb.org/Outreach/outreachPUblications/Project_factsheet/Egypt-ener-1-cc-undpspa.pdf

[16] Fernández Cuesta; La contabilidad y el Medio Ambiente. Técnica Contable. Vol. XLIV. N ${ }^{\circ}$ 522, Pp. 402 y 403. Junio, 1992.

[17] http://carbonfinance.org/

[18] http://documentacion.meh.es/doc/

[19] http://ec.europa.eu/environment/climat/pdf /eu_mechanisms_kyoto.pdf

[20] http://www.cesce.es/ 